University of Nebraska - Lincoln

DigitalCommons@University of Nebraska - Lincoln

Faculty Publications from the Harold W. Manter Laboratory of Parasitology

$10-2007$

\title{
Emended Description and Redetermination of Sarwaria caballeroi n. comb. (Nematoda: Ostertagiinae) with Details of the Synlophe and Esophageal Characters
}

\author{
Eric P. Hoberg \\ United States Department of Agriculture, eric.hoberg@ars.usda.gov \\ Arthur Abrams \\ United States Department of Agriculture
}

Follow this and additional works at: https://digitalcommons.unl.edu/parasitologyfacpubs

Part of the Parasitology Commons

Hoberg, Eric P. and Abrams, Arthur, "Emended Description and Redetermination of Sarwaria caballeroin. comb. (Nematoda: Ostertagiinae) with Details of the Synlophe and Esophageal Characters" (2007). Faculty Publications from the Harold W. Manter Laboratory of Parasitology. 328.

https://digitalcommons.unl.edu/parasitologyfacpubs/328

This Article is brought to you for free and open access by the Parasitology, Harold W. Manter Laboratory of at DigitalCommons@University of Nebraska - Lincoln. It has been accepted for inclusion in Faculty Publications from the Harold W. Manter Laboratory of Parasitology by an authorized administrator of DigitalCommons@University of Nebraska - Lincoln. 


\title{
EMENDED DESCRIPTION AND REDETERMINATION OF SARWARIA CABALLEROI N. COMB. (NEMATODA: OSTERTAGIINAE) WITH DETAILS OF THE SYNLOPHE AND ESOPHAGEAL CHARACTERS
}

\author{
Eric P. Hoberg and Arthur Abrams \\ United States Department of Agriculture, Agricultural Research Service, United States National Parasite Collection and Animal Parasitic \\ Disease Laboratory, BARC East 1180, 10300 Baltimore Avenue, Beltsville, Maryland 20705. e-mail: ehoberg@anri.barc.usda.gov
}

\begin{abstract}
Among genera of the ostertagiine nematodes, structural attributes of Spiculopteragia caballeroi are consistent with criteria that diagnose the genus Sarwaria. Specifically, the following characters are compatible with referral to this genus: (1) species characterized by monomorphic males; (2) tapering lateral synlophe in the cervical zone; (3) minuscule, thornlike cervical papillae; (4) length of Ray "4" < Ray "5"; (5) relatively thick or robust Ray "4"; (6) a substantially reduced dorsal lobe and dorsal ray that are disposed or curved ventrally relative to Rays "8"; and (7) a broad, laterally inflated dorsal lobe. Consequently, we propose Sarwaria caballeroi n. comb., and we provide further validation for the genus Sarwaria. Additionally, we propose that the ostertagiines are represented by 12 valid genera, including those characterized by a bursal formula of 2-2-1 (Cervicaprastrongylus, Hyostrongylus, Mazamastrongylus, Spiculopteragia, and Teladorsagia in addition to Sarwaria), and those in which the lateral rays describe a 2-1-2 pattern (Camelostrongylus, Longistrongylus, Marshallagia, Orloffia, Ostertagia, and Pseudomarshallagia).
\end{abstract}

Nematodes found in the abomasum and duodenum of an Asiatic chevrotain, Tragulus javanicus (Osbeck), collected near Kuala Lampur, Malaysia, were originally described as Spiculopteragia caballeroi Chabaud, 1977, and they were relegated among the Ostertagiinae. Among the ostertagiines, this species was considered by Chabaud (1977) to possess both "primitive and evolved" characters. Specimens were referred to Spiculopteragia (Orloff, 1933), regarded as the most ancestral genus of the Tribe Spiculopteragiini Sarwar, 1957 based on the absence of both a gubernaculum and cuticularized support structures in the genital cone of males, and occurrence in a primitive cervid (tragulid) host, although inconsistencies with this decision were noted (Chabaud, 1977).

In the current study, we examine these inconsistencies, and, based on new information for specific structural attributes, we propose a different generic taxonomy for this species. The synlophe, specifically the cervical region of males and females, was not described in detail, and it was otherwise not considered in the original taxonomic decision. The pattern of cuticular ridges in the cervical region, and other structural characters as addressed below, have a bearing on understanding the genericlevel placement for $S$. caballeroi.

Among the Ostertagiinae, several genera are characterized by a copulatory bursa in males in which the lateral rays describe a 2-2-1 pattern (Durette-Desset, 1983). Included here are the following: Spiculopteragia, Teladorsagia Andreeva and Satubaldin, 1954, Sarwaria Dróżdz, 1965, Mazamastrongylus Cameron, 1935, Hyostrongylus Hall, 1921, and Cervicaprastrongylus Gibbons and Khalil, 1982. Among this group, Spiculopteragia, Sarwaria, and Mazamastrongylus have been referred to the Spiculopteragiini (e.g., Sarwar, 1957; Dróżdz, 1965); Hyostrongylus and Cervicaprastrongylus to the Hyostrongyliini (Skrjabin and Shikhobalova, 1952) (e.g., Trach, 1986); and Teladorsagia to the Ostertagiini (e.g., Dróżdz, 1965), although most genera in this putative tribe have a 2-1-2 bursa. Spiculopteragiini was established by Sarwar (1957) for certain of the Ostertagiinae in Cervidae, Tragulidae, Suidae, and Bovidae, and it was defined as a discrete evolutionary lineage among the

Received 4 December 2006; revised 20 April 2007; accepted 20 April 2007 ostertagiines by Dróżdz (1965). The taxonomic partitioning for these tribes has received little attention, and phylogenetic support for these as independent lineages remains to be determined (e.g., Jansen, 1989). Furthermore, there is continued disagreement about the validity of certain genera among this group defined otherwise by bursal structure (e.g., Andreeva, 1957; Durette-Desset, 1981, 1982, 1983, 1989; Gibbons and Khalil, 1982; Jansen, 1989); resolution has some bearing on the generic placement of $S$. caballeroi.

Decisions by Durette-Desset $(1982,1983,1989)$ placed both Sarwaria and Mazamastrongylus (among others) as synonyms of Spiculopteragia. In contrast, Gibbons and Khalil (1982) regarded both as independent, whereas Jansen (1986) considered Mazamastrongylus discrete from Spiculopteragia. Lichtenfels et al. (1996), in agreement with Gibbons and Khalil (1982), reestablished the validity of Sarwaria.

Hyostrongylus had been referred to the Graphidiinae by Durette-Desset (1983); however, the validity of this genus (and Cervicaprastrongylus) as an ostertagiine was justified by Gibbons and Khalil (1982), Jansen (1989), Hoberg et al. (1993), and later by Durette-Desset et al. (1999). Durette-Desset and Chabaud $(1977,1981)$ and Durette-Desset $(1981,1985)$ postulated a close relationship for Hyostrongylus, Spiculopteragia (with Mazamastrongylus), and Teladorsagia; in phylogenetic analyses, these genera are placed in a polytomy basal to remaining Ostertagiinae (Durette-Desset et al., 1999) indicative of relationships diagnosed by bursal structure in this group (e.g., Hoberg and Lichtenfels, 1994).

Although bursal structure reflects putative phylogenetic diagnosis, characters of the synlophe and spicules may serve to provide unequivocal differentiation of specific genera. For example, the form of the tapering cervical synlope, with ventral "hood ridges" adjacent to the excretory pore, is a putative synapomorphy for Spiculopteragia + Mazamastrongylus; however, species of respective genera are characterized by unique configurations of terminal spicules (e.g., Lichtenfels et al., 1993; Hoberg, 1996; Hoberg and Khrustalev, 1996). Tapering synlophes in Teladorsagia and Sarwaria are similar (absence of hood ridges), but these genera are separated by the structure of the dorsal ray and spicules in the latter (e.g., Lichtenfels et al., 1988, 1996). Additionally, the parallel cervical synlophe seen 

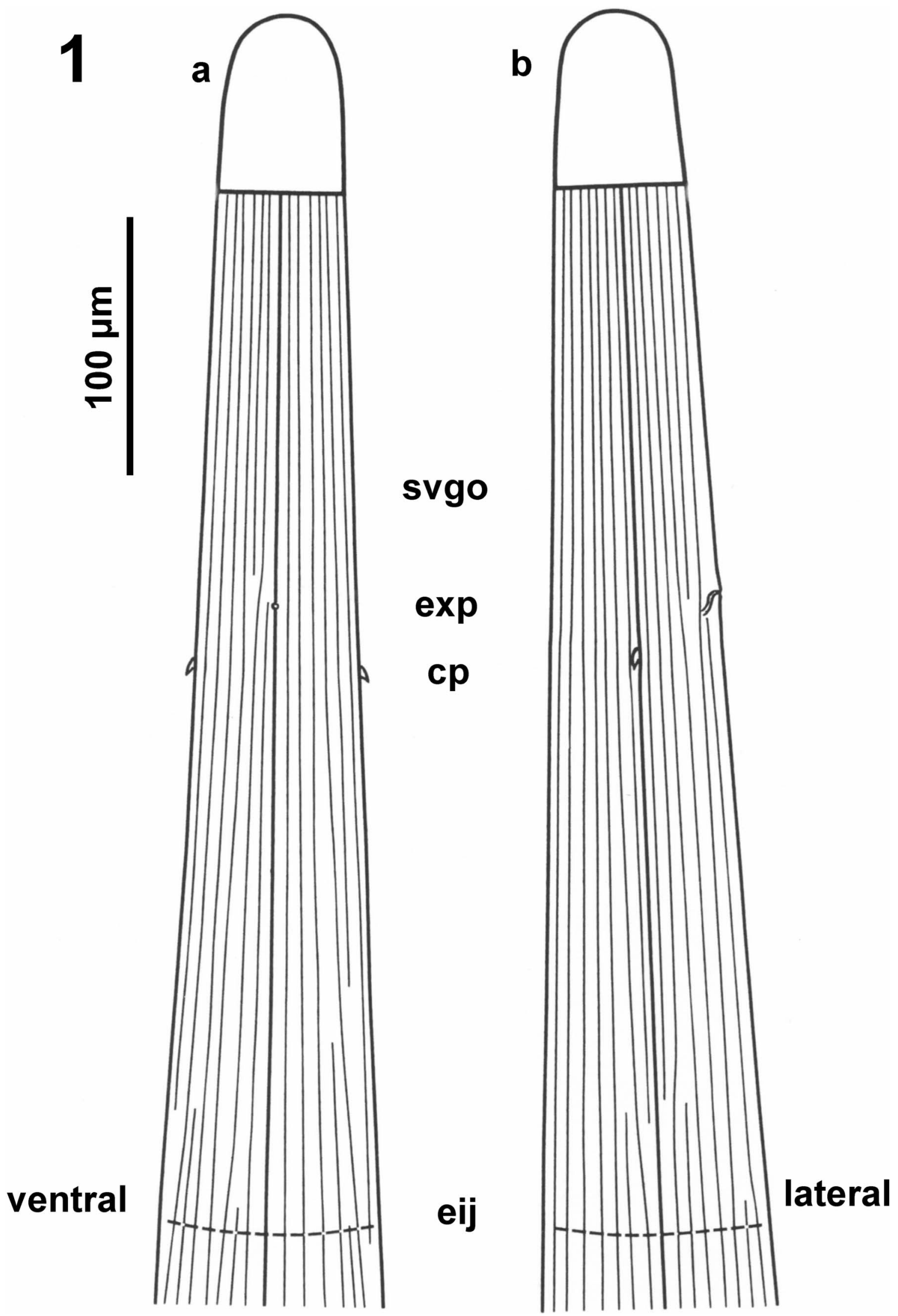

FIGURE 1. Sarwaria caballeroi $\mathrm{n}$. comb. showing structure of the synlophe in the cervical region and relative positions of the subventral gland orifices (svgo), excretory pore (exp), cervical papillae (cp), and EIJ (eij). (a) Ventral synlophe. (b) Lateral synlophe showing Type 1 Pattern for ostertagiines. 
in Hyostrongylus and Cevicaprastrongylus serves to distinguish these from other genera with a 2-2-1 bursal pattern (Hoberg et al., 1993).

In the current study, we provide an emended description of $S$. caballeroi based on examination of the type specimens. We focus on those suites of characters that were not evaluated in detail in the original description, particularly the structure of the cervical synlophe in males and females (e.g., Lichtenfels et al., 1988). These data contribute to a revision of Spiculopteragia (E.P.H. and A.A., data not shown), to reevaluation of the generic placement of $S$. caballeroi among the group distinguished by a 2-2-1 bursal formula, and to ongoing discussions about the systematic structure, validity, and relationships among putative genera of the ostertagiine nematodes (e.g., DuretteDesset, 1983; Jansen, 1989; Hoberg and Lichtenfels, 1994; Durette-Desset et al., 1999).

\section{MATERIALS AND METHODS}

\section{Nematode specimens}

The type specimens were obtained from the Collection de Zoologie du Museum National d'Histoire Naturelle, Paris, France (MNHN Paris: $881 \mathrm{LL})$. These specimens included the male holotype and female allotype in T. javanicus. Although the original article reports 14 male and 16 female specimens (Chabaud, 1977), these specimens were not made available for the current study.

\section{Microscopy}

The male and female type specimens were studied as temporary whole mounts cleared in phenol-alcohol ( 80 parts melted phenol crystals and 20 parts absolute ethanol) and examined with differential in terference contrast light microscopy. The male specimen was evaluated on the basis of the copulatory bursa, spicules, and genital cone. Bursal ray patterns were determined and described using the system of DuretteDesset and Chabaud (1981). Papillae of the genital cone and rays of the bursa followed the numbering system of Chabaud et al. (1970). The length of the valve at the esophageal-intestinal junction (EIJ), determined to extend from the posterior end of the cuticular lining of the triradiate lumen of the esophagus to the posterior end of the esophagus, was measured. The pattern of the cervical synlophe follows definitions outlined by Lichtenfels et al. (1988). Additionally, the structure of the ovejectors in females was evaluated in the context of recent definitions and descriptions among related nematodes (Lichtenfels et al., 2003). All measurements are given in micrometers, unless specified otherwise. Measurements determined for the type specimens in the current study do not differ substantially from those in the original description (Chabaud, 1977), so they are not repeated below.

\section{REDESCRIPTION}

\section{Spiculopteragia caballeroi Chabaud, 1977}

(Figs. 1-20)

General redescription: Trichostrongyloidea, uncoiled small nematodes. Cephalic vesicle present, poorly developed, buccal capsule miniscule, elongate and rounded with cuticularized lining. Deirids, small, thornlike (haemonchine) in confirmation, situated posterior to excretory pore and subventral gland orifice. Cuticle with prominent synlophe extending from base of cephalic expansion to near caudal extremity in males and females. EIJ prominent, length $<2 \times$ width.

Synlophe: Ridge system in cervical zone and throughout body in males and females, bilaterally symmetrical, perpendicular, lateral-most ridges relatively diminutive, otherwise lacking gradient in size, continuous, originating at base of cephalic expansion. Cervical zone with 14 ridges in dorsal and ventral fields, single right and left lateral ridges, total of 30; increasing in number posteriad from base of esophagus. In male, ridges terminate ventrally and dorsally near 320 anterior to prebursal papillae; lateral ridges terminate near 200-290. In female, ridges extend beyond the anus to the distal-most annulated portion of tail. Cervical synlophe tapering, consistent with "Type 1 Pattern" for ostertagiines with 1 pair of lateral ridges terminating in lateral field adjacent to the lateralmost ridge anterior to the EIJ. Ventrally, cervical synlophe parallel, Type A Pattern for ostertagiines, with ventral-most ridge interrupted by the excretory pore slightly anterior to cervical papillae.

Male characters: Single male morphotype. Valve at EIJ measuring $70 \times 45$. Bursal pattern 2-2-1. Paired "0" papillae miniscule, ventral to cloaca. Rays " 2 " and " 3 " equal in length, parallel in proximity, separating distally, convergent at tips. Ray " 2 " narrower than Ray " 3 ." Ray "4" robust, shorter than Ray "5." Accessory bursal membrane $(\mathrm{ABM})$ of genital cone, large and rounded, weakly incised ventrally, positioned dorsal to cloaca. Paired "7" papillae divergent laterally, curving ventrally within ABM, extending to distal end of ABM. Externodorsal, Ray " 8 ," with prominent medial curve distally. Dorsal lobe reduced, positioned ventrally relative to Rays " 8 ," with slight indentation distally; dorsal ray bipartite. Spicules, short, thick, trifurcate with main shaft of left spicule shorter than right; distal end of main shaft finely tapered with ventral curve. Gubernaculum absent.

Female characters: Valve at EIJ measuring $82 \times 45$. Amphidelphic with paired ovejectors, eggs present in anterior and posterior uteri. Ovejectors with common central vestibule, bipartite sphincters, and relatively short infundibula. Sphincter-1, muscular, bulblike; spincter-2 cylindrical, with poorly demarcated junction indicated by muscular construction at proximal end; length of posterior and anterior sphincters equal. Vulva, transverse, disposed ventrally. Vulval flaps and fans not

FiguRES 2-4. Sarwaria caballeroi n. comb., showing cephalic and cervical structures. (2) Cervical region in male holotype, ventral view, showing position of the subventral gland orifices (svgo), cervical papillae (cp), and form of the valve demarcating the EIJ (eij). (3) Cervical region in male, lateral view, showing position of miniscule, thornlike cervical papilla. (4) Cervical region in male, lateral view, showing structure of the excretory pore.

FiguREs 5-7. Sarwaria caballeroi n. comb., showing characters of the female genital system. (5) Ovejectors, lateral view, showing structure of vulva (vu), anterior and posterior infundibula (inf; between dotted lines and arrows), sphincters (sp) (between white arrows) demarcated as sphincter 1 (s1) and sphincter 2 (s2), and vestibule (ve). (6) Vulva, ventral view, showing structure of hypertrophied synlophe. (7) Eggs in posterior arm of uterus.

FIGURES 8-10. Sawaria caballeroi $\mathrm{n}$. comb., showing structure of tail in female. (8) Tail, ventral view, showing position of anus (an), phasimids (ph), and cuticular annulations (ann) near tip. (9) Anus, lateral view, showing absence of inflated cuticle. (10) Tail, lateral view, showing termination of synlophe (ts) in region posterior to anus (arrow), and cuticular annulations (ann). 


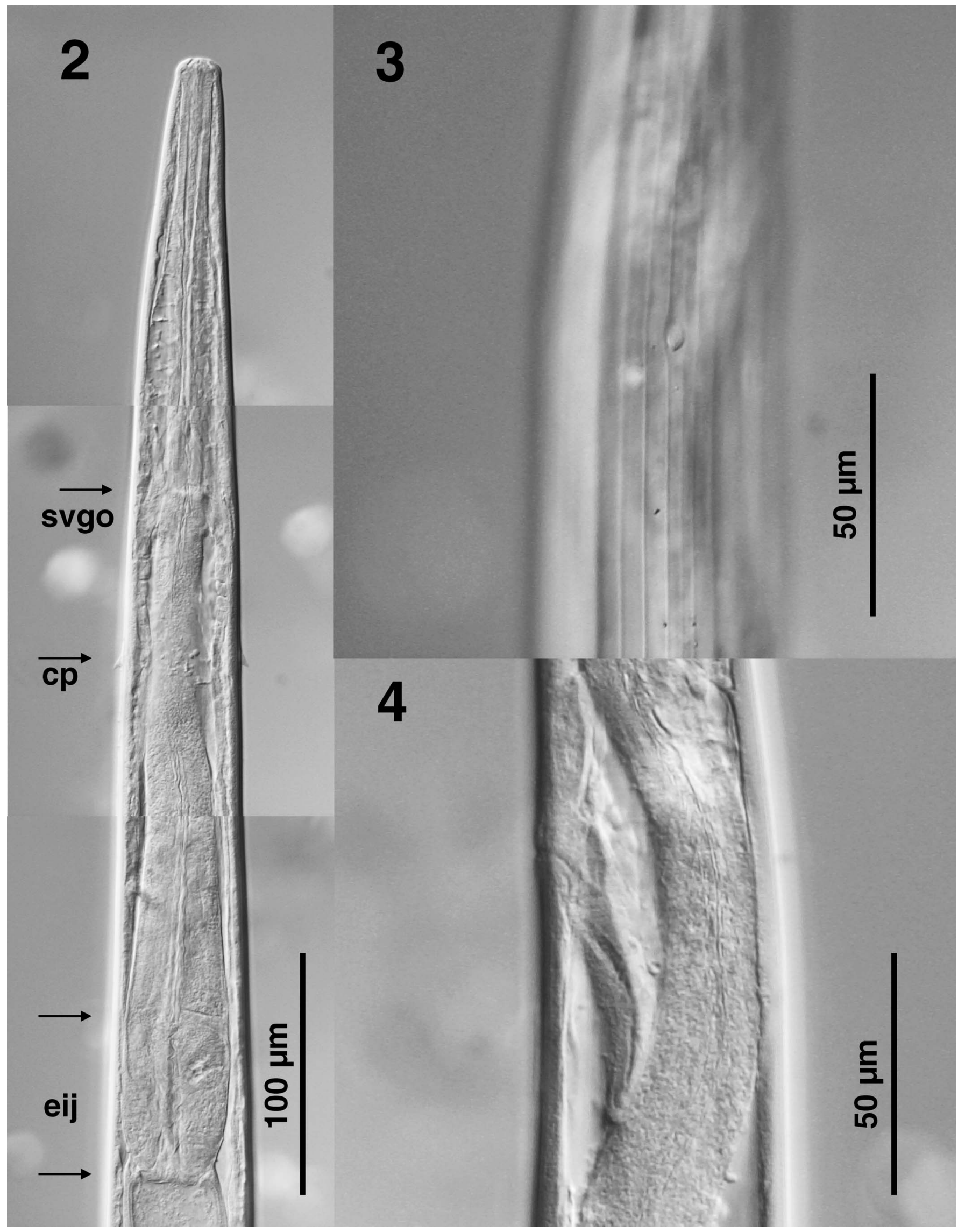




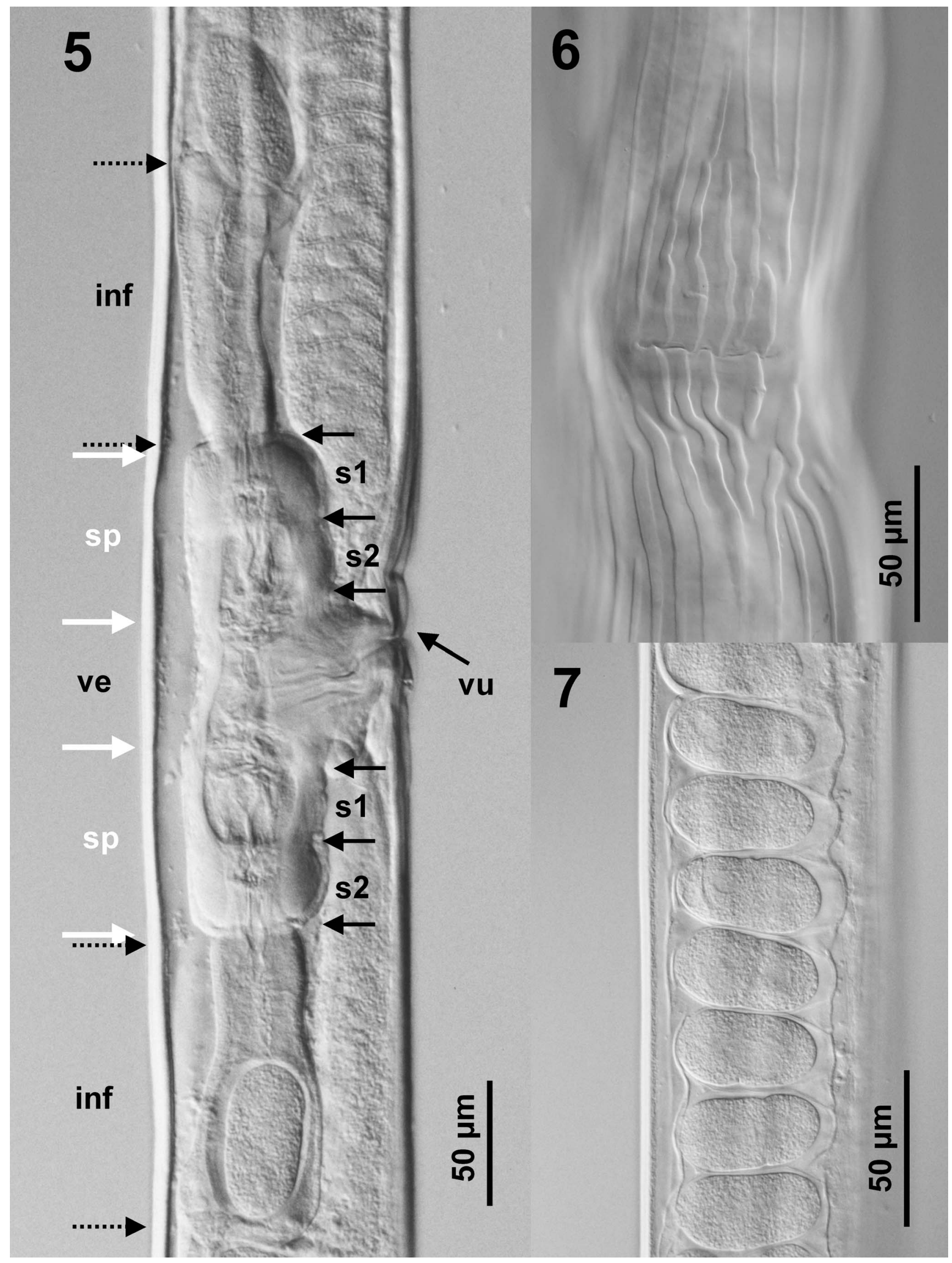




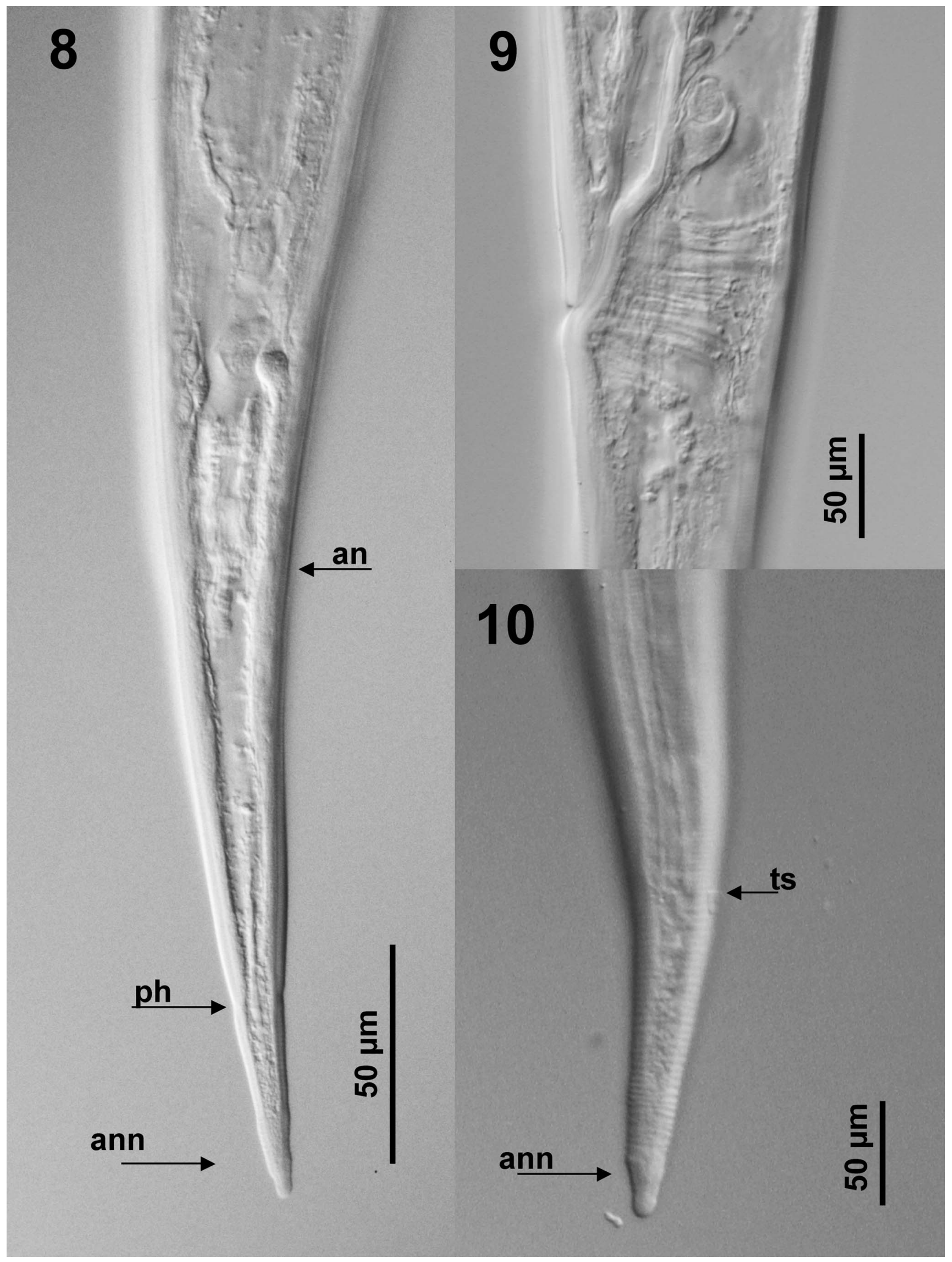




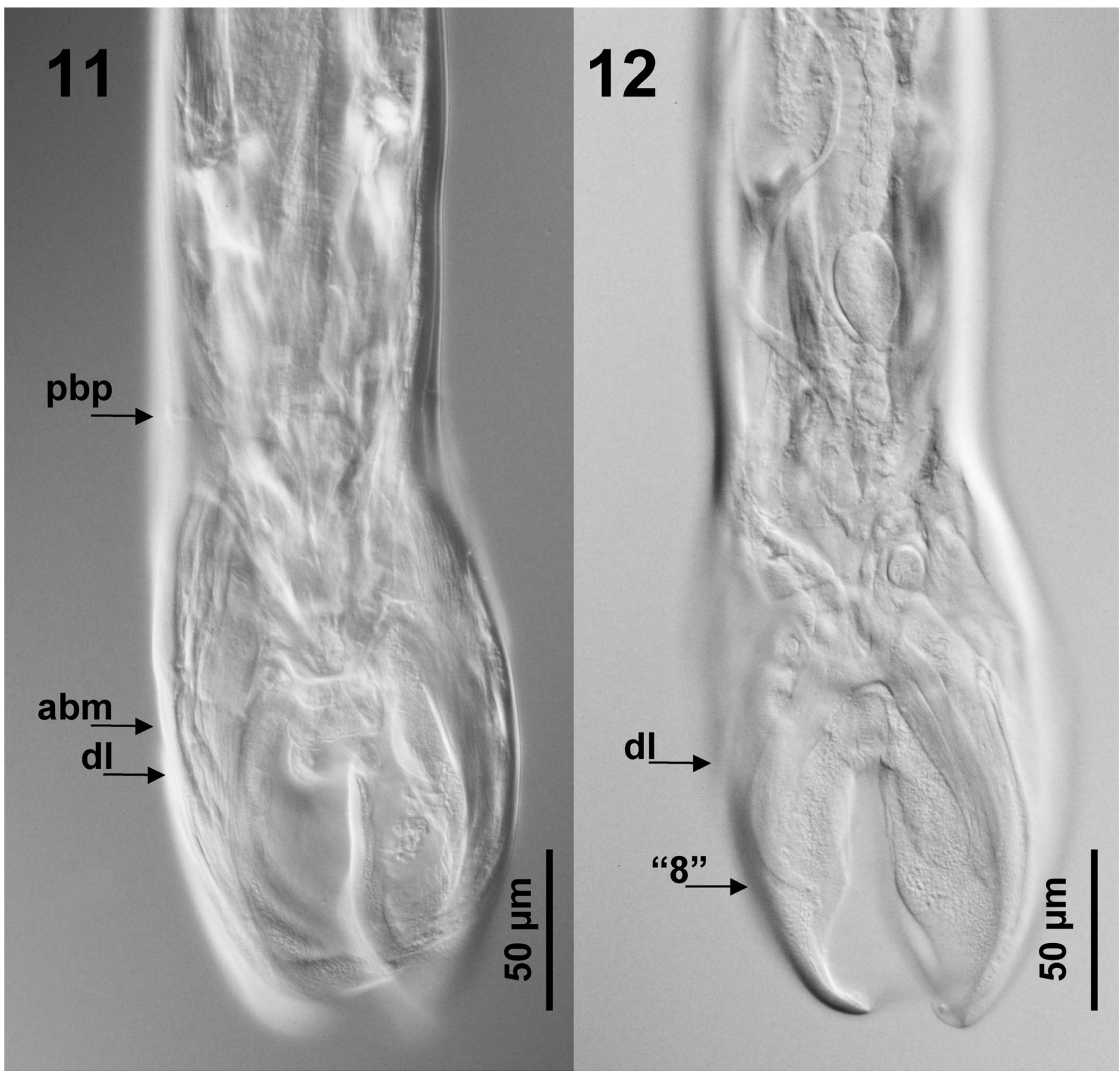

FIGURES 11-12. Sarwaria caballeroi n. comb., showing structure of copulatory bursa in male holotype. (11) Bursa, ventral view, showing positions of prebursal papillae (pbp), ABM (abm), and reduced dorsal lobe (dl). (12) Bursa, dorsal view, showing position of reduced dorsal lobe (dl) in plane ventral to curved externodorsal or " 8 " rays.

FiguRES 13-16. Sawaria caballeroi n. comb., showing characters of the male holotype. (13) Dorsal lobe, ventral view, showing relative position within copulatory bursa. (14) Copulatory bursa, lateral view, showing structure and position of Rays "2" and "3." (15) Spicule in right lateral view, showing thick, stout structure, with acute main shaft $(\mathrm{m})$, sinuous ventral process (v) and dorsal process (d). (16) Spicule, lateral view, main shaft, showing expanded region anterior to acutely pointed tip. 


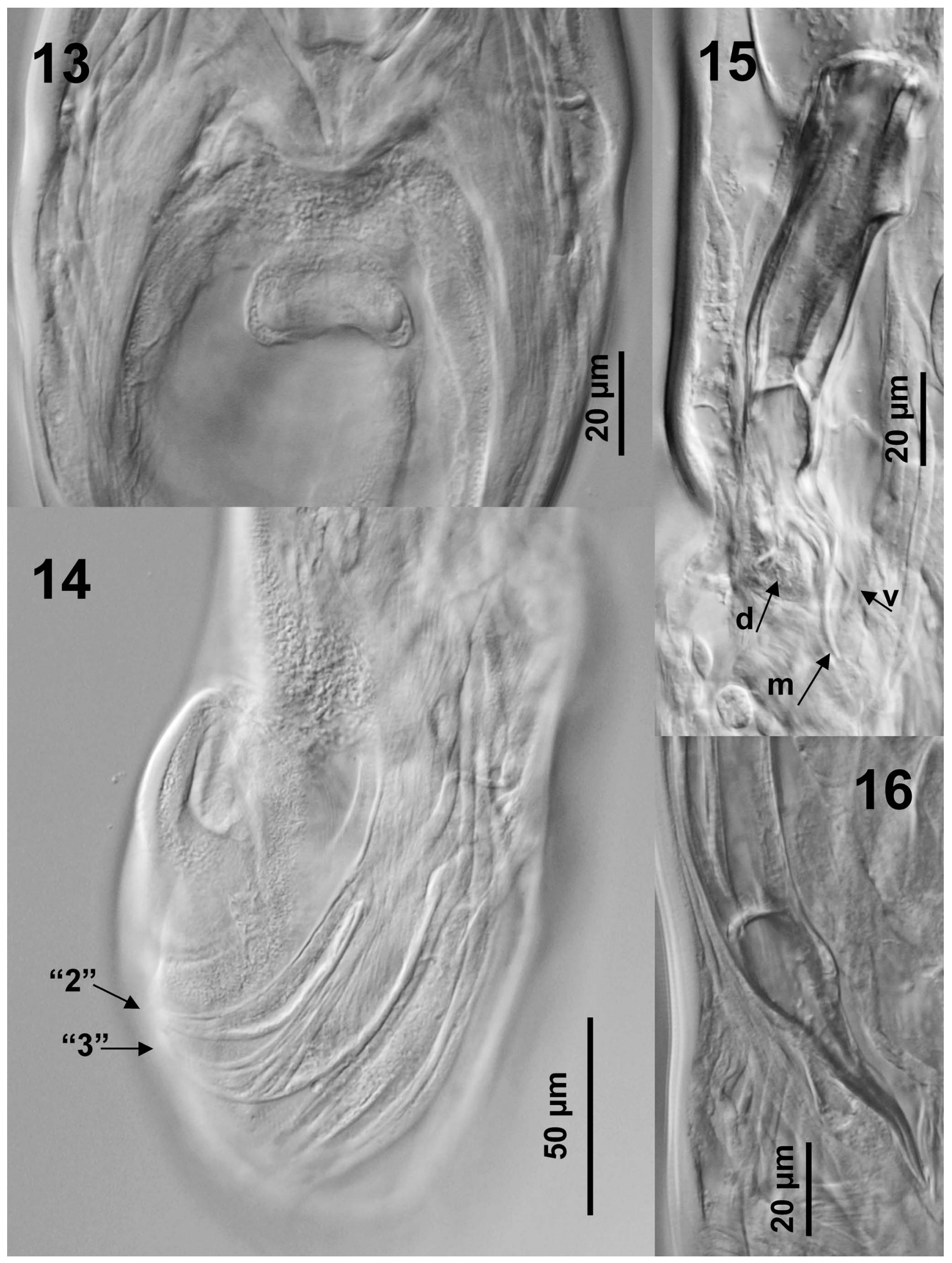




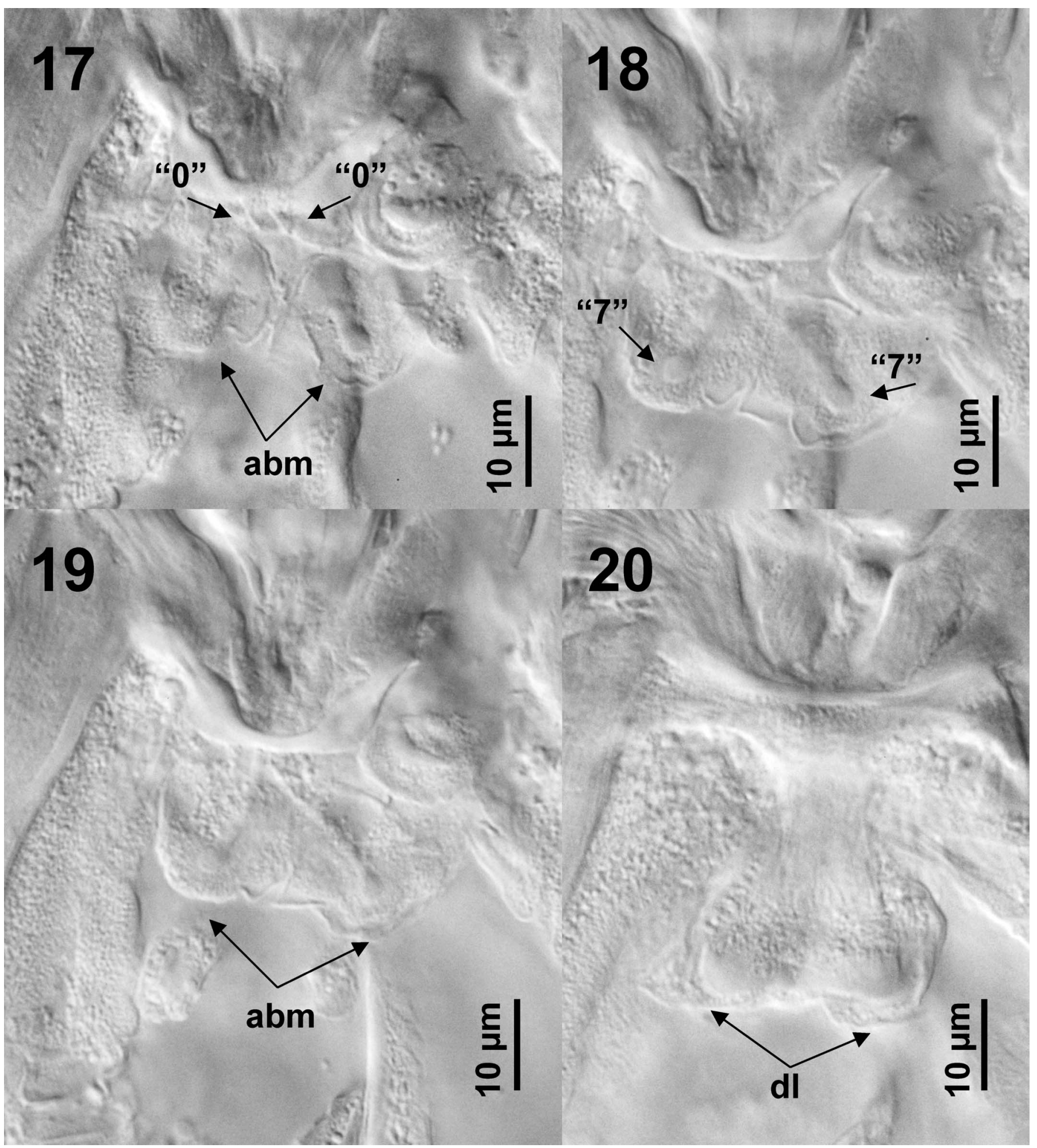

FiguRES 17-20. Sarwaria caballeroi n. comb., showing structure of genital cone and dorsal lobe. (17) Genital cone, ventral view, showing position of "0" papillae and ABM (abm). (18) Accessory bursal membrane, ventral view, containing paired and divergent "7" papillae. (19) ABM, ventral view, with focus toward dorsal lobe. (20) Dorsal lobe (dl), ventral view, showing laterally inflated structure and robust, reduced, dorsal ray. 
observed laterally or ventrally in alloptype; ridges of synlophe hypertrophied ventrally adjacent to vulva. Vulva at $81 \%$ of body length from anterior extremity. Tail, narrow, elongate, relatively acute, with cuticular annulations near tip.

\section{Comparisons and taxonomic position for S. caballeroi}

Ostertagiine taxonomy: Specimens of $S$. caballeroi are referred to the Ostertagiinae based on the presence of paired " 0 " papillae, a putative synapomorphy for this group of trichostrongyloids (Hoberg and Lichtenfels, 1994). The proper generic placement of S. caballeroi within the Ostertagiinae is guided by the presence of a 2-2-1 bursal ray pattern. The 2-2-1 pattern constitutes the apomorphic form of the bursa and also delimits Spiculopteragia, Mazamastrongylus, Cervicaprastrongylus, Hyostrongylus, and Teladorsagia in addition to Sarwaria (e.g., Hoberg and Lichtenfels, 1994; Durette-Desset et al., 1999). Historically, distinctions among these genera have been established on the basis of differences in spicule morphology, the genital cone, and dorsal ray with recent advances in the understanding of the cervical synlophe adding an additional level of refinement to our understanding of the systematics for these taxa. Among these genera, S. caballeroi is immediately distinguished from Hyostrongylus and Cervicaprastrongylus by the lateral tapering synlophe, Type 1, in the cervical region (Hoberg et al., 1993).

Comparisons with Spiculopteragia, Mazamastrongylus, and Teladorsagia: Chabaud (1977) assigned S. caballeroi to the genus Spiculopteragia within the tribe Spiculopteragiini on the basis of characteristics considered primitive, such as the lack of a gubernaculum and chitinized support structures within the genital cone, but noted the difficulty of accommodating this species among various genera of the ostertagiines. Spiculopteragia caballeroi shares with Mazamastrongylus and Spiculopteragia a 2-2-1 arrangement of the bursal rays and an absence of a gubernaculum. In contrast, bursal Rays " 2 " and " 3 " of $S$. caballeroi are parallel throughout their length, whereas these rays in all other species of Spiculopteragia are strongly divergent along their length but are convergent distally. The cervical synlophe in S. caballeroi differs substantially from the ventral (hood-ridges) and dorsal systems, which are postulated as a synapomorphy for Spiculopteragia and Mazamastrongylus (Lichtenfels et al., 1993; Hoberg, 1996). Additionally, the spicules of $S$. caballeroi do not possess putative synapomorphies unique to Spiculopteragia (prominent fan-shaped membranes) or Mazamastrongylus (spoon-shaped dorsal process) (Hoberg, 1996). Furthermore, S. caballeroi differs from species of Teladorsagia in the disposition of Rays " 2 " and "3," relative length of Ray " 4 ," and in structure of the dorsal lobe and ray, among other structural attributes (Hoberg et al., 1999). These observations establish that $S$. caballeroi cannot be referred to Spiculopteragia, Mazamastrongylus, or Teladorsagia.

Proposal for placement of S. caballeroi in the genus Sarwaria: Structural attributes of $S$. caballeroi are consistent with criteria that diagnose the genus Sarwaria (e.g., Gibbons and Khalil, 1982; Lichtenfels et al., 1996). Specifically, the following characters are compatible with referral to this genus: (1) species characterized by monomorphic males; (2) tapering lateral synlophe in cervical zone; (3) minuscule, thornlike cervical papillae; (4) length of Ray " 4 " < Ray "5"; (5) relatively thick or robust Ray "4"; (6) a substantially reduced dorsal lobe and dorsal ray that are disposed or curved ventrally relative to Rays " 8 "; and (7) a broad, laterally inflated dorsal lobe. Consequently, we propose Sarwaria caballeroi $\mathrm{n}$. comb.

\section{DISCUSSION}

\section{Ostertagiine taxonomy}

A revised concept for Sarwaria would now include 2 species, namely, the type $S$. bubalis (Sarwar, 1956), with synonyms $S$. boevi Pande and Chahaun, 1969 and Skrjabinagia bubalis Jiang, Guam, Yan and Zhou, 1988, and the proposed S. caballeroi n. comb. Inclusion of a second species in this genus, and clarification of morphological criteria as outlined, further support recognition of Sarwaria as a independent genus among the ostertagiine nematodes (e.g., Gibbons and Khalil, 1982; Lichtenfels et al., 1996).

In this concept, the Ostertagiinae would contain a minimum of 12 valid genera. We recognize 6 genera with a putative phylogenetic diagnosis based on the 2-2-1 pattern of the bursa, including Spiculopteragia, Mazamastrongylus, Cervicaprastrongylus, Hyostrongylus, and Teladorsagia in addition to Sarwaria. Furthermore, 6 other ostertagiine genera, with the plesiomorphic 2-1-2 bursal pattern, would include Camelostrongylus Orloff, 1933, Longistrongylus Le Roux, 1931, Marshallagia (Orloff, 1933), Orloffia Dróżdz, 1965, Ostertagia Ransom, 1907, and Pseudomarshallagia (Roetti, 1941). Such a proposal remains to be confirmed in the context of phylogenetic analyses designed specifically to resolve generic-level relationships, but it would expand the number of valid genera from that proposed or recognized by Jansen (1989) and Durette-Desset (1983, 1985, 1989) and Durette-Desset et al. (1999).

\section{Host associations and biogeography}

Species of Sarwaria parasitize either Bovinae or Tragulidae in southeast Asia and the Indian subcontinent (Sarwar, 1956; Pande and Chauhan, 1969; Chabaud, 1977), although it is apparent that $S$. bubalis has been widely disseminated in tropical and subtropical regions throughout the world coinciding with the introduction of water buffalo (Bubalis bubalis L.) and subsequent contemporary host switching to cattle (Lichtenfels et al., 1996). Assuming origins and endemism in Asia for species of Sarwaria, occurrence in bovid and tragulid hosts may be consistent with historical host colonization in a geographically constrained regional setting. Such a phenomenon has been proposed more generally as the basis for diversification among various trichostrongyloids occurring in ungulates (e.g., DuretteDesset, 1985). Among the related haemonchines and species of Haemonchus Cobb, 1898, geographic and host colonization have been postulated as dominant divers for speciation for assemblages of parasites in artiodactyls (Hoberg et al., 2004).

\section{ACKNOWLEDGMENTS}

We thank Jean-Lou Justine and Jimmy Cassone of the Museum National de Histoire Naturelle and the Collection Helminthe, Paris, France, for making the type specimens of $S$. caballeroi available for study.

\section{LITERATURE CITED}

AndreEVA, N. K. 1957. [Revision of Ostertagia (Trichostrongylidae) of ruminants] Trudy Instituta Veterinarri, Kazakhskii Filiala Vsesoyuznoi. Sel'skokhozyaistvennykh Nauk im. V.I. Lenina 8: $473-$ 487.

Chabaud, A. G. 1977. Spiculopteragia caballeroi sp. nov. nematode Trichostrongylidae parasite de Tragulus javanicus. In Excreta parasitològica en memoria del Doctor Eduardo Caballero y Caballero. Universidad Nacional Autònoma de México, Mexico City, Mexico, p. 415-418.

, F. Puylaert, O. Bain, A. J. Petter, and M.-Cl. DuretteDESSET. 1970. Remarques sur l'homologie entre les papilles cloacales des Rhabdites et les côtes dorsales des Strongylida. Comptes Rendus Hebdomadaire des Séances de 1'Academie des Sciences, Paris 271: 1771-1774.

DróżDZ, J. 1965. Studies on helminths and helminthiasis in Cervidae. I. Revision of the subfamily Ostertagiinae Sarwar, 1956 and an attempt to explain the phylogenesis of its representatives. Acta Parasitologica Polonica 13: 455-481.

Durette-Desset, M.-C. 1981. A hypothesis on the systematic position of the Ostertagiinae within the Trichostrongyloidea. In Workshop no. 14, systematics and biology of Ostertagia sens. lat. (Nematoda: Trichstrongylidae), J. Jansen and L. M. Gibbons (eds.). Parasitology 82: 175-177. 
1982. Sur les divisions génériques des Nématodes Ostertagiinae. Annales de Parasitologie Humaine et Comparée 57: 375-381.

. 1983. Keys to the genera of the superfamily Trichostrongyloidea, volume 10. In $\mathrm{CIH}$ keys to the nematode parasites of vertebrates, R. C. Anderson and A. G. Chabaud (eds.). Commonwealth Agricultural Bureaux, Farnham Royal, U.K., 86 p.

. 1985. Trichostrongyloid nematodes and their vertebrate hosts: Reconstruction of the phylogeny of a parasitic group. Advances in Parasitology 24: 239-306.

. 1989. Nomenclature proposée pour les espèces décrites dans la sous-famille des Ostertagiinae Lopez-Neyra, 1947. Annales de Parasitologie Humaine et Comparée 64: 356-373.

, AND A. G. Chabaud. 1977. Essai de classification des Nématodes Trichostrongyloidea. Annales de Parasitologie Humaine et Comparée 52: 539-558.

- AND - 1981. Nouvel essai de classification des Nématodes Trichostrongyloidea. Annales de Parasitologie Humaine et Comparée 56: 297-312.

, J. P. Hugot, P. Darlu, and A. G. Chabaud. 1999. A cladistic analysis of the Trichostrongyloidea (Nematoda). International Journal for Parasitology 29: 1065-1086.

Gibbons, L. M., And L. F. Khalil. 1982. A key for the identification of genera of the Nematode family Trichstrongylidae Leiper, 1912 Journal of Helminthology 56: 185-233.

Hoberg, E. P. 1996. Emended description of Mazamastrongylus peruvianus (Nematoda: Trichostrongylidae), with comments on the relationships of the genera Mazamastrongylus and Spiculopteragia. Journal of Parasitology 82: 470-477.

, AND A. V. Khrustalev. 1996. Re-evaluation of Mazamastrongylus dagestanica (Trichostrongylidae) with descriptions of the synlophe, genital cone, and other structural characters. Journal of Parasitology 82: 778-787.

, AND J. R. LiCHTENFELS. 1994. Phylogenetic systematic analysis of the Trichostrongylidae (Nematoda) with an initial assessment of coevolution and biogeography. Journal of Parasitology 80: 976996.

AND L. M. GibBons. 2004. Phylogeny for species of Haemonchus (Nematoda: Trichostrongyloidea): Considerations of their evolutionary history and global biogeography among Camelidae and Pecora (Artiodactyla). Journal of Parasitology 90: 10851102.

AND P. A. PilitT. 1993. Synlophe of Hyostrongylus rubidus (Trichostrongylidae), with evaluation of structural charac- ters supporting affiliation with the Ostertagiinae. Journal of the Helminthological Society of Washington 60: 219-233.

, K. J. Monsen, S. Kutz, and M. S. Blouin. 1999. Structure, biodiversity, and historical biogeography of nematode faunas in Holarctic ruminants: Morphological and molecular diagnoses for Teladorsagia boreoarcticus n. sp. (Nematoda: Ostertagiinae), a dimorphic cryptic species in muskoxen (Ovibos moschatus). Journal of Parasitology 85: 910-934.

JANSEN, J. 1986. Redescription of Mazamastrongylus trinitatis Cameron, 1935 and a discussion on the systematic position and species composition of the genus Mazamastrongylus Cameron, 1935 (Nematoda: Trichostrongyloidea). Systematic Parasitology 8: 279-283.

. 1989. A concise history of the Ostertagiinae Lopez-Neyra, 1947 (Nematoda: Trichostrongylidae) and a discussion on its composition. Acta Leidensia 58: 151-159.

Lichtenfels, J. R., E. P. Hoberg, P. A. Pilitt, And A. M. G. Belem 1993. A comparison of cuticular ridge patterns and other morphological characters of Mazamastrongylus odocoilei and Mazamas trongylus pursglovei (Nematoda: Trichostrongyloidea) from whitetailed deer Odocoileus virginianus. Systematic Parasitology 24: 115.

- P. A. PilitT, And T. M. CRaig. 1996. The synlophe and other structural characteristics of Sarwaria bubalis (Nematoda: Trichostrongyloidea) from cattle in Guyana. Journal of Parasitology 82: $146-154$.

, P. A. Pilitt, And L. M. GibBons. 2003. Ovejector structure in the Haemonchinae (Nematoda: Trichostrongyloidea) of ruminants. Journal of Parasitology 89: 984-993.

- AND M. B. LANCASTER. 1988. Cuticular ridge pattern of seven species of Ostertagiinae (Nematoda) parasitic in domestic ruminants. Proceedings of the Helminthological Society of Washington 55: 77-86.

PAnde, B. B., And P. P. S. Chauhan. 1969. Abomasal lesions in a trichostrongyloid infection of buffalo calves (below two years), and the morphology, and taxonomy of the nematode. Indian Journal of Animal Science 36: 79-88.

SARWAR, M. M. 1956. Studies on some trichostrongylids of ruminants from the Indo-Pakistan sub-continent. Biologia 2: 145-215.

- 1957. Observations on the morphology of Spiculopteragia asymetrica (Ware 1925) and a discussion on its relationship. Zeitschrift für Parisitenkunde 18: 1-4.

TrACH, V. N. 1986. Ekologo-faunistichheskaia kharacteristika polovozrelykh strongilat domashnikh zhavachnikh ukrainy. Akademiia Nauk Ukrainskoii SSR, Institut Zoologii, Kiev Naukova Dumka, Russia, 214 p. 